\title{
The relationship between self efficacy, hardiness and perceived stress amongst professional dancers
}

\author{
Shivali Shinde ${ }^{1}$, Vaishnavi Verma ${ }^{2}$, Archana Patki ${ }^{3}$ \\ ${ }^{1}$ Post Graduate student, Department of Psychology, Shri. Maniben M.P.Shah Women's College of Arts and \\ Commerce, Mumbai. \\ ${ }^{2}$ Assistant Professor, Department of Psychology, Shri. Maniben M.P.Shah Women's College of Arts and Commerce, \\ Mumbai. \\ ${ }^{3}$ Professor and Head, Department of Psychology, Shri. Maniben M.P.Shah Women's College of Arts and Commerce, \\ Mumbai. \\ E-mail - vaishnavi.verma1086@gmail.com
}

\begin{abstract}
Background: Stress and self efficacy are important variables related to performance and skill in the case of professional dancers. The purpose of this study was to see the correlation between self efficacy, hardiness and perceived stress in professional dancers. Dance affects the overall personality of an individual. Dance can improve mental health of an individual. Professional dancer is the performer who dances professionally and requires the innate talent to interpret and communicate stories and feelings through the physical form.

Methodology: Professional dancers of the age group of 25-35 were given questionnaires of General Self Efficacy (GSE), Hardiness scale (HS), Perceived Stress Scale (PSS) and the findings were statistically analyzed.

Results: The findings revealed a significant correlation between all the three variables amongst professional dancers. The $\mathrm{r}$ value was found to be significant at 0.01 level. There was a positive correlation between self efficacy and hardiness and negative correlation between self efficacy and perceived stress, and hardiness and perceived stress.

Conclusions: Further studies in larger samples along with better psychological scales and variables are essential to consolidate the results of the current study.
\end{abstract}

Key Words: stress, self efficacy, hardiness, dance, dancers.

(Paper received $-24^{\text {th }}$ April 2016, Peer review completed $-4^{\text {th }}$ June 2016, Accepted $-9^{\text {th }}$ June 2016)

\section{INTRODUCTION}

Dance affects the overall personality of an individual. Dance can improve mental health of an individual. Regular dance practice helps to prevent and treat mood disorders and depression. Dance class has enhanced self-esteem and a greater capacity to deal with everyday problems. Dance can be a wonderful, life enriching experience that provides you with a meaning, satisfaction, and joy in an art form that promotes health, cultivates relationships and extends your physical, psychological and emotional horizons. It can fuel passion, boost confidence, engender positive emotions and encourage a life full of engagement, drive and focus. Yet for some, dance becomes harmful experience that is physically debilitating, emotionally crippling and socially damaging. Because of the extreme nature of dance, it can be a breeding ground and an outlet for unhealthy aspects of personality that hurt self esteem, promote health obsessiveness, and lead to a life of anxiety , frustration and unhappiness [1-2]. 
According to the Institute of Dance Movement therapy (DMT), dance is a 'form of psychotherapy which uses creative movement and dance as a process to further emotional, physical, cognitive and social integration within a therapeutic relationship [3].

A professional dancer is the performer who dances professionally. Being a professional dancer requires the innate talent to interpret and communicate stories and feelings through the physical form. There are four characteristics of a professional dancer. They are physical strength, creativity, teamwork and persistence. Dancing involves a careful blend of physical and psychological characteristics .without physical fitness and stamina, dancers cannot successfully perform. Dancers require creativity, which helps them to express the music and story lines they dance to using unique body movements. This artistic ability allows dancers to communicate ideas through physical expression, and come up with new ideas to add to dance routines. The sense of musicality, such as in rhythm, goes along with the creativity that dancers need to perform well [4-5].

\section{Self efficacy}

According to Albert Bandura self-efficacy is one's own belief in one's ability to succeed in specific situations or accomplish a task. One's sense of self efficacy can play a major role in how one approaches goals, tasks, and challenges. It is the ability to persist and a person's ability to succeed with a task. High and low self-efficacy determines whether or not someone will choose to take on a challenging task or "write it off" as impossible. Self-efficacy affects every area of human endeavour. By determining the beliefs a person holds regarding his or her power to affect situations, it strongly influences both the power a person actually has to face challenges competently and the choices a person is most likely to make. These effects are particularly apparent, and compelling, with regard to behaviours affecting health [6-7].

\section{Social cognitive theory}

The theory of self-efficacy lies at the centre of Bandura's social cognitive theory which emphasizes the role of observational learning and social experience in the development of personality. The main concept in social cognitive theory is that an individual's actions and reactions, including social behaviours and cognitive processes, in almost every situation are influenced by the actions that individual has observed in others. Because self-efficacy is developed from external experiences and self-perception and is influential in determining the outcome of many events, it is an important aspect of social cognitive theory. Self-efficacy represents the personal perception of external social factors. According to Bandura's theory, people with high self-efficacy - that is, those who believe they can perform well-are more likely to view difficult tasks as something to be mastered rather than something to be avoided [8-9].

\section{Social learning theory}

Social learning theory describes the acquisition of skills that are developed exclusively or primarily within a social group. Social learning depends on how individuals either succeed or fail at dynamic interactions within groups, and promotes the development of individual emotional and practical skills as well as accurate perception of self and acceptance of others. According to this theory, people learn from one another through observation, imitation, and modelling. Self-efficacy reflects an individual's understanding of what skills he/she can offer in a group setting [10-11].

\section{Self concept theory}

Self-concept theory seeks to explain how people perceive and interpret their own existence from clues they receive from external sources, focusing on how these impressions are organized and how they are active throughout life. Successes and failures are closely related to the ways in which people have learned to view themselves and their relationships with others. This theory describes self-concept as learned (i.e., not present at birth); organized (in the way it is applied to the self); and dynamic (i.e., ever-changing, and not fixed at a certain age) [12]. 


\section{Hardiness}

Hardiness is the ability to endure difficult conditions. In the early days of hardiness research, it was usually defined as a personality structure comprising the three related general dispositions of commitment, control, and challenge that functions as a resistance resource in the encounter with stressful conditions. The commitment disposition was defined as a tendency to involve oneself in the activities in life and having a genuine interest in and curiosity about the surrounding world (activities, things, other people). The control disposition was defined as a tendency to believe and act as if one can influence the events taking place around oneself through one's own effort. Finally, the challenge disposition was defined as the belief that changes rather than stability, is the normal mode of life and constitutes motivating opportunities for personal growth rather than threats to security [13-14].

Lately, Maddi has characterized hardiness as a combination of three attitudes (commitment, control, and challenge) that together provide the courage and motivation needed to turn stressful circumstances from potential calamities into opportunities for personal growth [15]. While acknowledging the importance of the three core dimensions, Baritone considers hardiness as something more global than mere attitudes. He conceives of hardiness as a broad personality style or generalized mode of functioning that includes cognitive, emotional, and behavioural qualities. This generalized style of functioning, which incorporates commitment, control, and challenge, is believed to affect how one views oneself and interacts with the world around [16]. The hardy personality is one that has a large amount of commitment, control and challenge. People who exhibit hardy personalities are less likely to suffer the ill effects that stress can cause on the mind and body. The personality they exhibit can buffer out the effects of stress has on people.

A study by the International Association for Dance, Medicine and Science focuses on physiological changes associated with the adolescent growth spurt can temporarily diminish a dancer's technical proficiency and increase vulnerability to injuries. The loss of technique in combination with normal adolescent emotional challenges can lead to lack of confidence and low self-esteem. Health care practitioners should work in collaboration with dance teachers, students, and their parents to build a bridge between the science and art of dance. So this study is in favour of the present study that dancers with physical injury can improve their self esteem and self efficacy [17].

Dance has an impact on stress and life satisfaction among corporate professionals. A comparative study was conducted on 60 participants from the corporate sector divided into dancers $(n=30)$ and non-dancers $(n=30)$, within the age group of 20-40 years. Results showed no significant impact of dance on stress and life satisfaction which implied that social factors like gender differences, nature of work, family dynamics, coping strategies, etc influences dance [18].

A study focused on Self efficacy and social support as mediator between culturally specific dance and lifestyle physical activity. An experimental design compared intervention and control groups for mediating effects of self-efficacy and social support on lifestyle physical activity. Findings indicated that only outcome expectations and social support from friends mediated effects. Culturally specific dance is a first step in encouraging African American women to become more physically active and improve health outcomes. The implications are that culturally specific dance programs can improve health outcomes by including members of underserved populations [19].

Another research investigated the relationship of hardiness to stress and to performance, and explored its moderating effect on the relationship between stress and performance. Three hundred twenty-six officer cadets in the Israel Defence Forces completed self-report stress questionnaires during four critical course events and hardiness questionnaires at the beginning and end of the course. As hypothesized, hardiness was consistently negatively related to experienced stress. It was also consistently positively related to objectively assessed performance throughout the course and in the subsequent course, and to the first onthe-job performance appraisal a year later. In addition to its main effects, hardiness buffered the cadets from the detrimental effects of stress on performance. So this study again supports the present study that there is a correlation between hardiness and perceived stress [20]. 


\section{METHODOLOGY}

Participants - The population being studied is adult professional dancers within the age group of 25-35 years. Gender was not a matter of constraint in the study and both males and females were allowed to be a part of the study. The sample obtained was through the Purposive sampling which is a non probability sampling strategy. A purposive sample is one that is selected based on the knowledge of the population and the purpose of the study. It is where the subjects are selected because of some characteristics which they possess.

\section{Variables studied -}

Self efficacy - Self efficacy is one's own belief in one's ability to succeed in specific situations or accomplish a task. The ability to persist and a person's ability to succeed with a task.

Hardiness - Hardiness is defined as personality structure comprising the three related general dispositions of commitment, control, and challenge that functions as a resistance resource in the encounter with stressful conditions.

Perceived stress - Perceived stress is an extent to which persons perceive that their demands exceed their ability to cope. It is a state of mental or emotional strain or tension resulting from adverse or demanding situations.

Professional dancer - Professional dancers are those who are performing on a professional level that includes theatre productions, TV shows, movies and dance recitals. They should have at least experience of one year as a professional.

Controls - Individuals in the age range of 25-35 years and having minimum education till SSC and residing in Mumbai city will be allowed to participate in this study.

\section{Tools used in the study -}

General Self Efficacy Scale (GSES): General Self Efficacy Scale is developed by Schwarzer, R., and Jerusalem, M. in 1995. This is a self report scale, which can be administered on Adolescents and Adults. This 10 item scale was created to assess a general sense of perceived self efficacy. The reliability of this test was 0.80 , internal consistency was 0.76 to 0.90 , with the majority in the high 0.80 s. The range is from 10 to 40 point. There is no cut off score [21].

Hardiness scale: Hardiness scale is developed by S.O. Kobasa. This is a self report scale measuring the level of hardiness. This scale measures three main aspects that are control, commitment and challenge. This is a 12 item scale. Scoring was done manually [22].

Perceived Stress Scale (PSS): Perceived Stress Scale is developed by Sheldon Cohen in 1983. Perceived stress scale measures the self perception of stress. It is a measure of degree to which situations in one's life are appraised as stressful. Items were designed to tap how unpredictable, uncontrollable and overloaded respondents find their lives [23].

The study undertaken is an applied study to understand the relationship between self efficacy, hardiness and perceived stress among professional dancers. 100 professional dancers were each individually given the selected tests - General self efficacy scale, hardiness scale and perceived stress scale. Participants were verbally informed of the time period within which the tests needed to be returned.

\section{STATISTICAL ANALYSIS}

After administration of the test, the raw scores were obtained. Thereafter, the appropriate scoring procedures for the three tests were followed in order to obtain an accurate measure of self efficacy, hardiness and perceived stress. For further analysis of the data collected Pearson's Product moment correlation was calculated to investigate the relationship between self efficacy, hardiness and perceived stress among professional dancers 


\section{RESULTS}

The objective of the present study was to measure the level of self efficacy, hardiness and perceived stress among professional dancers, and to see the correlation between all the three variables.

Descriptive statistics and correlations of the three variables have been given in table 1 and 2 respectively.

Table 1 shows the Mean and SD of the three variables; self efficacy, hardiness and perceived stress. According to the table 1, mean score of general self efficacy scale was 32.31. SD was 3.08. Mean score of hardiness scale was 9.12 and SD was 3.61. And mean score for perceived stress scale was 12.04 and SD was 4.04 .

Table 1 - The scores on the scales for various variables

\begin{tabular}{|l|l|l|l|}
\hline \multicolumn{4}{|l|}{ Descriptive Statistics } \\
\hline & Mean & $\begin{array}{l}\text { Std. } \\
\text { Deviation }\end{array}$ & $\mathrm{N}$ \\
\hline GSE & 32.31 & 3.080 & 100 \\
\hline $\begin{array}{l}\text { Hardiness } \\
\text { scale }\end{array}$ & 9.12 & 3.619 & 100 \\
\hline PSS & 12.04 & 4.040 & 100 \\
\hline
\end{tabular}

Table 2 describes the correlations of the three variables. The product moment correlation was computed to understand the nature of relationship between self efficacy, hardiness and perceived stress. The calculations and statistical analysis was done using the SPSS software version 20 . The $\mathrm{r}$ value found to be significant at 0.01 level. According to the obtained scores the correlation between two variables that was self efficacy and hardiness was 0.381 which is significant (two tailed). So the relationship between self efficacy and hardiness was positive. The correlation between self efficacy and perceived stress was -. 070 which was again significant (two tailed). That means the relationship between these two variables self efficacy and perceived stress was negative. The correlation between hardiness and perceived stress was 0.34 which was significant (two tailed). So that means the relationship between hardiness and perceived stress was negative.

Table 2 - The Correlation Table

\begin{tabular}{|c|c|c|c|c|}
\hline \multicolumn{5}{|c|}{ Correlations } \\
\hline & & GSE & $\begin{array}{l}\text { Hardiness } \\
\text { scale }\end{array}$ & PSS \\
\hline \multirow[t]{2}{*}{ GSE } & $\begin{array}{l}\text { Pearson } \\
\text { Correlation }\end{array}$ & 1 & $.381^{* *}$ & -.070 \\
\hline & $\begin{array}{l}\text { Sig. (2- } \\
\text { tailed) }\end{array}$ & & .000 & .489 \\
\hline \multirow[t]{2}{*}{$\begin{array}{l}\text { Hardiness } \\
\text { scale }\end{array}$} & $\begin{array}{l}\text { Pearson } \\
\text { Correlation }\end{array}$ & $.381^{* *}$ & 1 & .034 \\
\hline & $\begin{array}{l}\text { Sig. (2- } \\
\text { tailed) }\end{array}$ & .000 & & .741 \\
\hline \multirow[t]{2}{*}{ PSS } & $\begin{array}{l}\text { Pearson } \\
\text { Correlation }\end{array}$ & -.070 & .034 & 1 \\
\hline & $\begin{array}{l}\text { Sig. (2- } \\
\text { tailed) }\end{array}$ & .489 & .741 & \\
\hline
\end{tabular}




\section{DISCUSSION}

According to the results, the correlation for first research problem was found to be significant and there was a positive correlation between self efficacy and hardiness among professional dancers. Higher the self efficacy, higher will be the hardiness among professional dancers. These results are in line with a study which examined the interrelationship between quality of life, hardiness, self efficacy, self esteem among working and non working married women. The results of the study indicate that the women with higher quality of life score rank also on higher on hardiness, self efficacy and self esteem and vice versa. According to the results of correlations for second research problem was found to be negative correlation between self efficacy and perceived stress among professional dancers. Higher the self efficacy lower will be the perceived stress level in professional dancers.

According to a past study which examined the relationship between perceived stress and psychological capitol (a combination of self efficacy, optimism, hope and resilience) among young entrepreneur, it was found that the entrepreneurs reported low level of perceived stress as they were high on self efficacy, hope, optimism and resilience [24]. A study tried to investigate the relationship of hardiness to stress and to performance, and to explore its moderating effect on the relationship between stress and performance, the results found that the hardiness buffered the cadets from the detrimental effects of stress on performance [25].

The limitation of the study is that the researchers in this study have not considered other factors or precursors of stress such as experience of stress producing life events or absence of social support, even the other professions of professional dancers. The sample of the study consisted of only 100 professional dancers. A larger sample could have led to greater understanding of the differences in the relationship of self efficacy, hardiness and levels of stress. The sample belonged to one city.

This study was basically done to see the relationship between the self efficacy, hardiness and perceived stress among professional dancers. So the use of this study could be that through this study we explored that higher the self efficacy and hardiness the lower will be the level of stress among professional dancers. And this is not only limited to the field of professional dancers but also applicable to all kinds of professions and to all kinds of population. Usually the stress can have negative impact on the self efficacy and hardiness but this study indicates that if one has high level of self efficacy and high level of hardiness won't get affected by the degree of stress perceived from their profession or workplace and not just that but also other life stressors like death of a loved one or family finances etc. So being positive and hopeful will definitely increase the tolerance level of stress and stress won't affect much on our day to day life.

Further research can be done by taking different variables like resilience and hope and post traumatic stress, optimism or anxiety and many more. Large amount of sample could have let to greater understanding of the differences in the relationship of self efficacy, hardiness and level of stress.

\section{REFERENCES}

1. Burkhardt J, Brennan C. The effects of recreational dance interventions on the health and well-being of children and young people: A systematic review. Arts Health 2012;4(2):148-61.

2. Arts Council England A. Dance and health: The benefits for people of all ages. Arts council England; 2006.

3. Payne H. Dance movement therapy: Theory and practice. Routledge; 2003.

4. Stanton-Jones K. An introduction to dance movement therapy in psychiatry. Taylor \& Francis; 1992.

5. Jeong YJ, Hong SC, Lee MS, Park MC, Kim YK, Suh CM. Dance movement therapy improves emotional responses and modulates neurohormones in adolescents with mild depression. Int $\mathrm{J}$ Neurosci 2005;115(12):1711-20.

6. Bandura A. Self-efficacy mechanism in human agency. Amer Psychol 1982;37(2):122-9.

7. Bandura A. Self-efficacy: The exercise of control. Macmillan; 1997.

8. Bandura A. Social cognitive theory. Handbook of social psychological theories. 2011.

9. Bandura A. Social cognitive theory: An agentic perspective. Ann Rev Psychol 2001;52(1):1-26.

10. Rotter JB. The development and applications of social learning theory: Selected papers. Praeger Publishers; 1982.

11. Bandura A. Social learning theory Englewood Cliffs ; 1977.

12. Wylie RC. The self-concept: Theory and research on selected topics. U of Nebraska Press; 1974. 
13. Epstein S. The self-concept revisited: Or a theory of a theory. Amer Psychol 1973;28(5):404-34.

14. Maddi SR, Khoshaba DM. Hardiness and mental health. J Personal Assess 1994;63(2):265-74.

15. Florian V, Mikulincer M, Taubman O. Does hardiness contribute to mental health during a stressful real-life situation? The roles of appraisal and coping. J Personal Soc Psychol 1995;68(4):687-99.

16. Pengilly JW, Dowd ET. Hardiness and social support as moderators of stress. J Clin Psychol 2000;56(6):81320.

17. Heber L. Dance movement: A therapeutic program for psychiatric clients. Persp Psychiatr Care 1993;29(2):22-9.

18. Federici A, Bellagamba S, Rocchi MB. Does dance-based training improve balance in adult and young old subjects? A pilot randomized controlled trial. Aging Clin Exp Res 2005;17(5):385-9.

19. Bräuninger I. Treatment modalities and self-expectancy of therapists: Modes, self-efficacy and imagination of clients in dance movement therapy. Body Mov Dance Psychother 2006;1(2):95-114.

20. Waysman M, Schwarzwald J, Solomon Z. Hardiness: An examination of its relationship with positive and negative long term changes following trauma. J Traum Stress 2001;14(3):531-48.

21. Schwarzer R, Bäßler J, Kwiatek P, Schröder K, Zhang JX. The assessment of optimistic self-beliefs: comparison of the German, Spanish, and Chinese versions of the general self-efficacy scale. Appl Psychol 1997;46(1):69-88.

22. Bartone PT. Test-retest reliability of the dispositional resilience scale-15, a brief hardiness scale. Psychol Rep 2007;101(3):943-4.

23. Cohen S, Kamarck T, Mermelstein R. Perceived stress scale. Measuring stress: A guide for health and social scientists. 1994.

24. Lewis P, Bernstein P. Theoretical approaches in dance-movement therapy. Kendall Hunt Pub Co; 1986.

25. Bartone PT. Resilience under military operational stress: can leaders influence hardiness?. Military Psychol 2006;18:S131-8.

\author{
Acknowledgements - Nil \\ Source of Funding - Nil \\ Conflict of Interest - Nil
}

